City University of New York (CUNY)

CUNY Academic Works

2018

\title{
Observed Differences between Near-Surface Air and Skin Temperatures Using Satellite and Ground-based Data
}

Satya Prakash

CUNY New York City College of Technology

Farjana Shati

CUNY New York City College of Technology

Hamidreza Norouzi

New York City College of Technology

Reginald Blake

CUNY New York City College of Technology

\section{How does access to this work benefit you? Let us know!}

More information about this work at: https://academicworks.cuny.edu/ny_pubs/310

Discover additional works at: https://academicworks.cuny.edu

This work is made publicly available by the City University of New York (CUNY).

Contact: AcademicWorks@cuny.edu 
Observed differences between near-surface air and skin temperatures using satellite and ground-based data

\author{
Satya Prakash ${ }^{1,2^{*}}$, Farjana Shati ${ }^{1}$, Hamid Norouzi ${ }^{1,3}$, and Reginald Blake ${ }^{1}$ \\ ${ }^{1}$ New York City College of Technology, \\ City University of New York, \\ Brooklyn, NY 11201, USA \\ ${ }^{2}$ Divecha Centre for Climate Change, \\ Indian Institute of Science, \\ Bengaluru, 560012, India \\ ${ }^{3}$ Earth and Environmental Sciences, \\ The Graduate Center, City University of New York, \\ New York, NY 10016, USA \\ *Corresponding author's email: sprakash012@gmail.com
}

Theoretical and Applied Climatology

doi:10.1007/s00704-018-2623-1 (Accepted on Sep 01, 2018) 
Abstract: Accurate estimates of long-term land surface temperature $\left(T_{s}\right)$ and near-surface air temperature $\left(T_{a}\right)$ at finer spatio-temporal resolutions are crucial for surface energy budget studies, for environmental applications, for land surface model data assimilation, and for climate change assessment and its associated impacts. The Atmospheric Infrared Sounder (AIRS) and Moderate Resolution Imaging Spectroradiometer (MODIS) sensors onboard the Aqua satellite provide a unique opportunity to estimate both temperatures twice daily at the global scale. In this study, differences between $T_{a}$ and $T_{s}$ were assessed locally over regions of North America from 2009 to 2013 using ground-based observations covering a wide range of geographical, topographical, and land cover types. The differences between $T_{a}$ and $T_{s}$ during non-precipitating conditions are generally 2-3 times larger than precipitating conditions. However, these differences show noticeable diurnal and seasonal variations. The differences between $T_{a}$ and $T_{s}$ were also investigated at the global scale using the AIRS estimates under clear-sky conditions for the period 2003-2015. The tropical regions showed about 5-20 ${ }^{\circ} \mathrm{C}$ warmer $T_{s}$ than $T_{a}$ during the day-time, whereas opposite characteristics (about $2-5{ }^{\circ} \mathrm{C}$ cooler $T_{s}$ than $T_{a}$ ) are found over most parts of the globe during the night-time. Additionally, $T_{s}$ estimates from the AIRS and the MODIS sensors were inter-compared. Although large-scale features of $T_{s}$ were essentially similar for both sensors, considerable differences in magnitudes were observed $\left(>6{ }^{\circ} \mathrm{C}\right.$ over mountainous regions). Finally, $T_{a}$ and $T_{s}$ estimates from the AIRS and MODIS sensors were validated against ground-based observations for the period of 2009-2013. The error characteristics notably varied with ground stations and no clear evidence of their dependency on land cover types or elevation was detected. However, the MODIS-derived $T_{s}$ estimates generally showed larger biases and higher errors compared to the AIRS-derived estimates. The biases and errors increased steadily when the spatial resolution of the MODIS estimates changed from finer 
to coarser. These results suggest that representativeness error should be properly accounted for when validating satellite-based temperature estimates with point observations.

Keywords: Near-surface air temperature; Skin temperature; Polar-orbiting satellite; Groundbased observations; Land cover

\section{Introduction}

Reliable estimates of land surface temperature (skin temperature or LST or $T_{s}$ ) and nearsurface air temperature $\left(T_{a}\right)$ are vital for surface energy budget computations, for land surface model data assimilation, for environmental applications, and for trend assessments and their associated impacts (Houser et al., 2010; Mazdiyasni and AghaKouchak, 2015; Stephens and L'Ecuyer, 2015; Cheval and Dumitrescu, 2017; Rahmstorf et al., 2017; Ruzmaikin et al., 2017). Estimates of $T_{s}$ under clear-sky conditions from the Earth-observation satellites are readily available at global and regional scales. However, satellite-based estimates of $T_{a}$ are rather sparse, and available at coarse spatial and temporal resolutions. Moreover, ground-based observations of $T_{s}$ and $T_{a}$ suffer from limited spatial coverage.

Two Moderate Resolution Imaging Spectroradiometer (MODIS) sensors mounted on the Terra and Aqua satellites provide a unique opportunity to study the spatio-temporal variations of $T_{s}$ at global and regional scales. The Atmospheric Infrared Sounder (AIRS) sensor onboard the Aqua satellite provides $T_{a}$ and its vertical profile at coarse spatial resolution $(\sim 100 \mathrm{~km})$. The need of fine resolution homogeneous estimates of $T_{a}$ is realized for epidemiological and agricultural studies. $T_{s}$ products at finer spatial resolution derived from the MODIS sensors were widely utilized for $T_{a}$ estimation and for the study of intensity of urban heat islands (Ayanlade, 2016; 
Noi et al., 2016; Didari et al., 2017; Yang et al., 2017). Satellite remote sensing along with ground-based observations have been proven to be promising for the characterization and variability of different kinds of urban heat islands such as canopy layer heat island, boundary layer heat island, and surface heat island (Fabrizi et al., 2010; Ramamurthy and Sangobanwo, 2016; Cheval and Dumitrescu, 2017). However, satellite-derived geophysical products have errors due to sampling and algorithms. $T_{a}$ and $T_{s}$ estimates are also used as input datasets for estimating passive microwave land surface emissivity. The accuracy of these passive microwave land surface emissivity estimates largely depends on the error characteristics of the input datasets (Norouzi et al., 2011; Prakash et al., 2016, 2018). Hence, a comprehensive error characterization of these satellite-based $T_{s}$ and $T_{a}$ estimates is essential for their wider applicability.

The satellite infrared-based $T_{s}$ measurements have been widely used for the indirect estimation of $T_{a}$ (Good, 2016; Noi et al., 2016; Oyler et al., 2016; Didari et al., 2017; Sheng et al., 2017; Yang et al., 2017). Recently, Sheng et al. (2017) investigated the spatio-temporal relationship between $T_{a}$ and $T_{s}$ and its dependence on land cover types and elevation comprehensively over the southeastern China. $T_{s}$ estimates from the MODIS were compared with other satellite-based estimates (Lee et al., 2013; Urban et al., 2013; Kang et al., 2015), however the evaluation of $T_{s}$ and $T_{a}$ products from the Aqua satellite against ground-based observations is rather lacking. Furthermore, the quantification of differences among $T_{s}, T_{a}$, and upper-layer soil temperature is crucial for a wide range of applications (Gallo et al., 2011; Moncet et al., 2011; Norouzi et al., 2015; Prakash et al., 2017; Shati et al., 2018). Based on ground-based observations, Gallo et al. (2011) reported that although the magnitude of $T_{s}$ is generally greater than $T_{a}$, the differences between $T_{s}$ and $T_{a}$ are larger during the clear-sky than the cloudy-sky conditions. However, their study was limited over a few ground stations having 
nearly homogeneous land surface characteristics. A notable difference between $T_{a}$ and upperlayer soil temperature was also reported using ground-based observations (Shati et al., 2018).

The objective of this study is to critically assess the differences between $T_{s}$ and $T_{a}$ from the Aqua satellite and ground-based observations. The differences between these two variables are also evaluated for precipitating and non-precipitating conditions exclusively using groundbased observations. Additionally, $T_{s}$ estimates from the MODIS and the AIRS sensors are intercompared and validated with independent observations. It is to be noted that the infrared sensors provide $T_{s}$ and $T_{a}$ estimates only for the clear-sky conditions.

\section{Data and Methods}

\subsection{Satellite data}

The Aqua satellite, the first member of the afternoon constellation, was launched by the NASA on May 4, 2002 to collect a wide range of Earth system variables for better understanding of the global water and energy budget (Parkinson, 2013). There were six sensors onboard the satellite, namely: the Atmospheric Infrared Sounder (AIRS), the Moderate Resolution Imaging Spectroradiometer (MODIS), the Advanced Microwave Scanning Radiometer for the Earth Observing System (AMSR-E), the Advanced Microwave Sounding Unit (AMSU), the Clouds and Earth's Radiant Energy System (CERES), and the Humidity Sounder for Brazil (HSB). The local equatorial crossing times of this satellite are about 1:30 p.m. for the ascending orbits and about 1:30 a.m. for the descending orbits. The AIRS sensor makes measurements of atmospheric temperature, water vapor, trace gases, clouds and surface variables at 2378 infrared and 4 visible/near infrared channels. The MODIS makes finer spatial resolution measurements of atmospheric, oceanic and land surface parameters at 36 visible and infrared channels. In this 
study, infrared-based measurements of near-surface air temperature from the AIRS, and skin temperature estimates from the MODIS and AIRS under clear-sky conditions were used. The latest version (version 6) of daily level 3 gridded swath products from AIRS available at $1^{\circ}$ latitude/longitude resolution (Susskind et al., 2014), and from MODIS available at $0.05^{\circ}$ climate modeling grid (Wan, 2014) for the period of 2003 to 2015 were used. Comparison of versions 6 and 5 of the AIRS air temperature profiles with dropsonde observations over Antarctica, a region having complex surface and atmospheric conditions, showed a notable reduction of error in V6 by $25 \%$ as compared to V5 (Boylan et al., 2015). The improvements in bias and error in V6 estimates are primarily due to the inclusion of a new neural network based first guess approach, an improved cloud clearing algorithm, and rigorous quality control flags (Blackwell, 2012; Susskind et al., 2014). The AIRS datasets have been recently utilized for the study of diurnal cycle variability of the Earth surface temperature (Ruzmaikin et al., 2017). The MODIS-derived $T_{s}$ version 6 product showed larger magnitude than version 5 product, primarily over the arid regions (Prakash et al., 2018). The biases and errors in the MODIS-derived V6 product showed substantial improvement in $T_{s}$ over V5 product due to refinements in the split-window retrieval algorithm and the adjustment in the emissivity difference for bare soil (Wan, 2014). Additionally, the global land cover climatology available at $0.5 \mathrm{~km}$ based on the MODIS data for 2001 to 2010 (Broxton et al., 2014) were also utilized.

\subsection{Ground-based data}

The U. S. Climate Reference Network (USCRN) is a systematic and sustained network of more than 100 climate monitoring stations that measure air temperature, precipitation, soil moisture, soil temperature, solar radiation, wind speed, relative humidity, and wetness (the 
presence or absence of moisture due to precipitation as measured by wetness sensors and disdrometers) across the North America (Bell et al., 2013; Diamond et al., 2013). In order to maintain high accuracy and reliability in measurements, instruments at each station are calibrated annually and their performances are monitored on a daily basis. The observations are available at sub-hourly, hourly, daily, and monthly scales. Hourly quality-controlled precipitation, land surface temperature, and near-surface air temperature observations for 19 selected USCRN stations (Figure 1) for a 5-year period (2009-2013) were used in this study. These 19 stations were specially selected to cover a wide range of geographical, topographical, and vegetation categories (Table 1). The elevation of these stations varied from 11 meters to 1821 meters, and they covered six distinct land cover types.

\subsection{Methodology}

Since the Aqua satellite provides measurements twice daily at 01:30 and 13:30 local time, hourly ground-based observations from USCRN at two consecutive hours were linearly interpolated for comparison. For instance, USCRN observations of 01:00 and 02:00 hours were linearly interpolated for the comparison of Aqua measurements at 01:30 hours. It is to be noted that the linear interpolation of consecutive hours of observations would not significantly impact the comparison results, in general (Shati et al., 2018). This was also confirmed from the diurnal analyses of ground-based $T_{s}$ and $T_{a}$ observations that are discussed in the later section of this study. In order to compare the point observations with gridded satellite products, temperature values $\left(T_{s}\right.$ or $\left.T_{a}\right)$ of the satellite grid nearest to the station location were considered. Four error metrics - correlation coefficient $(r)$, bias, root-mean-square error (RMSE), and mean absolute 
error (MAE) given by equations (1) - (4) were used to evaluate the satellite-based products against the USCRN observations.

$$
\begin{aligned}
& r=\frac{\sum_{i=1}^{n}\left(O_{i}-O\right)\left(S_{i}-S\right)}{\left[\sum_{i=1}^{n}\left(O_{i}-O\right)^{2} \sum_{i=1}^{n}\left(S_{i}-S\right)^{2}\right]^{1 / 2}} \\
& \text { Bias }=S-O \\
& R M S E=\sqrt{\frac{\sum_{i=1}^{n}\left(S_{i}-O_{i}\right)^{2}}{n}} \\
& M A E=\frac{\sum_{i=1}^{n}\left|\left(S_{i}-O_{i}\right)\right|}{n}
\end{aligned}
$$

where, $S_{i}$ and $O_{i}$ are the satellite- and ground-based observations, $S$ and $O$ are their respective means, and $n$ is the total number of matches. It is to be noted that the computations with satellite data are performed only for clear-sky conditions, even though ground-based observations are available for all-weather conditions.

\section{Results}

\subsection{Differences between air and skin temperatures from USCRN observations}

In this section, the differences between concurrent $T_{a}$ and $T_{s}$ are assessed from the USCRN observations for the five-year period of 2009-2013. Since the selected 19 stations are located in different parts of North America and have distinct features (e.g., Figure 1), the assessment was done at each station separately. Two specific local times of 01:30 p.m. and 01:30 
a.m. corresponding to ascending and descending overpass times of the Aqua satellite were chosen for the analysis. Figure 2(a) shows the mean differences between $T_{a}$ and $T_{s}$ for precipitating and non-precipitating conditions during the day-time. As expected, the magnitudes of $T_{s}$ are generally greater than those for $T_{a}$ during the day-time. However, the differences are about 2-3 times larger during non-precipitating conditions than during precipitating conditions. About $5-6{ }^{\circ} \mathrm{C}$ higher $T_{s}$ than $T_{a}$ is evident during day-time, whereas about $1-2{ }^{\circ} \mathrm{C}$ lower $T_{s}$ than $T_{a}$ is observed during night-time (Figure 2(b)) for non-precipitation conditions. The mean differences also vary with station. Two stations - Williams and Monahans situated in open shrublands show exceptionally larger difference between $T_{a}$ and $T_{s}$. During non-precipitating conditions, the incoming solar radiation, and the difference in heat capacities between land and air play critical roles in producing the larger variations in $T_{a}$ and $T_{s}$. The solar radiation that is absorbed at the ground warms the surface, alters the air temperature (sensible heat), and vaporizes surface moisture and water (latent heat). Therefore, higher latent heat will cause larger difference between $T_{a}$ and $T_{s}$. The mean differences between $T_{a}$ and $T_{s}$ for precipitating and nonprecipitating conditions during night-time are shown in Figure 2(b). Interestingly, the magnitudes of $T_{a}$ are generally larger than those of $T_{s}$ during non-precipitating conditions. However, the magnitudes of differences are rather smaller during night-time than during the daytime. The differences between $T_{a}$ and $T_{s}$ are very small or negligible during precipitating conditions. The land surface essentially warms faster than the air in the presence of solar insolation during the day-time, and it also cools rapidly in the absence of insolation during the night-time. The corresponding standard deviations of difference between $T_{a}$ and $T_{s}$ for ascending and descending overpasses under non-precipitating and precipitating conditions are illustrated in Figures 2(c) and 2(d). The differences between $T_{a}$ and $T_{s}$ exhibit larger variability during day- 
time than night-time. Similarly, larger standard deviations of $T_{a}-T_{s}$ for non-precipitating conditions than precipitating conditions are observed.

In order to better understand the temporal variations of differences between $T_{a}$ and $T_{s}$, diurnal variability of $T_{a}$ and $T_{s}$ has been investigated. Figure 3 presents the diurnal variations of $T_{a}$ and $T_{s}$ from hourly USCRN observations (all-weather observations) for four selected stations. These four stations are situated in distinct land cover types. Due to the consistency and the availability of the USCRN datasets, four months in 2013 - January, April, July, and October were selected as the seasonal representatives of the northern hemisphere winter, spring, summer, and fall, respectively. In general, $T_{s}$ remained smaller than $T_{a}$ during the night-time to early morning and then increased thereafter as compared to $T_{a}$. The magnitude of $T_{s}$ became larger than $T_{a}$ between late morning and evening, and then decreased again from the evening. This general behavior of temperatures can be seen for all the seasons. However, the magnitudes of differences varied with season and location (Ayanlade, 2016; Good, 2016). The differences between $T_{a}$ and $T_{s}$ are largest during the summer season and smallest during the winter season. Moreover, the magnitude of difference between $T_{s}$ and $T_{a}$ during day-time is larger for cropland and grassland stations than those from the stations having land cover types of deciduous broadleaf forest and cropland/natural vegetation mosaic. The standard deviations of $T_{a}$ and $T_{s}$ are rather larger during the afternoon especially for the month of April. However, $T_{s}$ shows larger magnitude of standard deviation than $T_{a}$. These diurnal characteristics of differences between $T_{a}$ and $T_{s}$ are vital for the reliable estimation of $T_{a}$ from $T_{s}$ under all-weather conditions. 


\subsection{Differences between air and skin temperatures from AIRS data}

In this section, the differences between $T_{a}$ and $T_{s}$ have been assessed at the global scale using AIRS version 6 data. These estimates are available only for clear-sky conditions. Although the spatial resolution of the AIRS products is rather coarse ( $1^{\circ}$ latitude/longitude), it yet provides concurrent estimates of $T_{a}$ and $T_{s}$ from a single sensor. Figure 4 presents the spatial distributions of satellite-derived mean $T_{a}$ and $T_{s}$, and their difference for the 13-year period of 2003-2015. The analysis is done for ascending and descending overpasses separately. The tropical areas are warmer than the sub-tropical areas in terms of both $T_{a}$ and $T_{s}$, in general. The tropical arid regions show warmer $T_{s}\left(>42{ }^{\circ} \mathrm{C}\right)$ than $T_{a}$ during the day-time. The differences between both temperatures are prominent $\left(T_{a}-T_{s} \sim 10-20{ }^{\circ} \mathrm{C}\right)$ over the major desert areas primarily during the day-time, but they decrease notably during the night-time. $T_{a}$ shows about $2-5{ }^{\circ} \mathrm{C}$ larger magnitude than $T_{s}$ during the night-time over most parts of the globe. There is larger standard deviation in the difference is noticed during the day-time than the night-time. These results are in reasonably good agreement with the results obtained from the USCRN observations (e.g., Figure 2) in terms of diurnal variability of both temperatures.

Figure 5 presents the 13-year mean difference between $T_{a}$ and $T_{s}$ for the months of January and July for ascending and descending orbits of the AIRS sensor. The difference between $T_{a}$ and $T_{s}$ shows clear seasonal variations during the day-time. Larger day-time differences between $T_{a}$ and $T_{s}$ are clearly seen in the tropics due to significant solar heating. The differences between both temperatures are smallest in the extra-tropics. In general, the northern hemisphere is warmer than the southern hemisphere, because most of the large deserts lie in the northern hemisphere. The northern hemisphere shows larger differences in July (corresponds to northern summer) than January (corresponds to northern winter). $T_{s}$ shows generally larger 
magnitude of standard deviation than $T_{a}$, particularly during day-time. The difference in standard deviations between day-time $T_{a}$ and $T_{s}$ is larger over the northern hemisphere than the southern hemisphere in July, similar to the differences in mean $T_{a}$ and $T_{s}$ patterns (e.g., Figure 5).

\subsection{Comparison of MODIS and AIRS skin temperatures}

Since both MODIS and AIRS onboard the Aqua satellite provides clear-sky $T_{s}$ estimates at different spatial resolutions, their inter-comparison is instructive for understanding and perhaps reducing the error structure of satellite-derived geophysical products like $T_{s}$ for land surface applications. Additionally, an inter-comparison of MODIS and AIRS can yield insights about the consistency of both products. The MODIS sensor provides global $T_{s}$ estimates at finer spatial resolution than the AIRS sensor. The MODIS global $T_{s}$ product was resampled at two distinct spatial resolutions of $0.25^{\circ}$ and $1^{\circ}$ latitude/longitude apart from its native spatial resolution for the comparison with AIRS-derived $T_{s}$ estimates. Figure 6 presents the spatial distributions of mean monthly $T_{s}$ from MODIS at three distinct spatial resolutions and from AIRS for the ascending orbits of January 2012. Despite the large-scale features, $T_{s}$ estimates are qualitatively similar for both; however, there are considerable differences in magnitudes. The spatial distributions of differences between resampled MODIS and AIRS estimates, and a scatter plot of both sets of $T_{s}$ are also shown in the Figure 6. In general, the MODIS estimates show larger $T_{s}$ than the AIRS estimates over the tropical areas except near the equatorial region of Africa. The differences between both estimates are rather larger $\left(>6^{\circ} \mathrm{C}\right)$ over mountainous regions. The MODIS estimates exhibit notably lower $T_{s}$ than AIRS over the northern highlatitude regions. It is to be noted that the differences between MODIS and AIRS estimates could partly be explained due to resampling. The differences could be potentially due to uncertainties 
in retrieving skin temperature from MODIS observations too. In order to obtain $T_{s}$, accurate estimation of land surface emissivity is required which due to lack of ground-true values is hard to achieve, and may lead to inaccurate estimation of LST. Hence, these two $T_{s}$ estimates need to be evaluated against ground-based observations to obtain their error characteristics.

In order to investigate the large-scale changes in annual mean $T_{s}$ and $T_{a}$ during the Aquaera, differences between the last five years (e.g., 2011-2015) and the first five years (e.g., 20032007) of the study period were computed for ascending and descending overpasses. Figure 7 illustrates the spatial distributions of these differences for MODIS-based $T_{s}$, and AIRS-based $T_{s}$ and $T_{a}$ estimates. Both MODIS and AIRS based $T_{s}$ estimates show similar patterns, which are supported by $T_{a}$ estimates as well. Europe, Russia, and southern parts of North America show considerable warming between 2003 and 2015. However, Australia, India, northern China, northern parts of North America, and Alaska show noticeable cooling during this period. Although similar patterns can be seen in the ascending and descending overpasses, magnitudes are larger during day-time than night-time. However, despite being insightful, the 13-year period is inadequate for a complete robust trend analysis.

\subsection{Evaluation of satellite infrared-based air and skin temperatures}

In this section, satellite-based $T_{a}$ and $T_{s}$ estimates are evaluated against USCRN observations over North America for a five-year period from 2009 to 2013. The evaluation is performed at each USCRN stations separately for day-time and night-time. The stations cover a wide range of features and are located at different parts of the country (Figure 1). Figure 8 shows the comparison of Aqua-based infrared $T_{a}$ and $T_{s}$ estimates against ground-based observations for a specific site at Millbrook, NY for the day-time. The MODIS-derived $T_{s}$ estimates are 
compared at three distinct spatial resolutions. The satellite-based temperature estimates show statistically significant high correlation coefficient when compared to ground-based observations. The AIRS underestimates $T_{a}$ by $0.7^{\circ} \mathrm{C}$ when compared to USCRN observations, and RMSE and MAE of the satellite estimates are $2.2^{\circ} \mathrm{C}$ and $1.7^{\circ} \mathrm{C}$, respectively. However, the bias and errors are larger in $T_{s}$ than $T_{a}$ in the AIRS product. The MODIS-derived $T_{s}$ estimates show rather larger underestimation and higher errors compared to AIRS-derived estimates. The biases and errors gradually amplify with decrease (e.g., from finer to coarser) in spatial resolutions. This result clearly reveals that the representativeness error increases with coarser resolutions of satellite-based temperature estimates, when compared with ground-based observations. Comparison of gridded satellite estimates with ground-based point measurements would essentially explain some discrepancies in terms of representativeness error.

Figure 9 illustrates the bias, correlation coefficient, RMSE and MAE in satellite-based $T_{a}$ and $T_{s}$ estimates compared to ground-based observations for each USCRN stations for the daytime, while Figure 10 shows these statistics for night-time. In general, both AIRS and MODIS estimates systematically underestimate $T_{a}$ and $T_{s}$ during the day-time, whereas the magnitude of biases is rather smaller during the night-time. Moreover, the underestimation or overestimation of temperatures by the AIRS and MODIS vary for all stations. The satellite-derived $T_{a}$ and $T_{s}$ estimates show exceptionally smaller correlation with ground-based observations during both day and night times at a station located at Merced, CA. The magnitudes of MAE and RMSE are also larger for this station. At Darrington, WA, the satellite-derived $T_{a}$ and $T_{s}$ estimates are in good agreement $(r>0.9)$ with ground-based observations during the day-time, but the correlation is smaller during the night-time. Although errors in the satellite-based estimates are smaller during the night-time than the day-time, no clear dependency of errors with land cover 
type or elevation is observed. These results would essentially be useful for the estimation of $T_{a}$ from satellite-based $T_{s}$ estimates.

\section{Discussion}

The satellite-based $T_{a}$ and $T_{s}$ estimates were evaluated against ground observations from 19 USCRN stations over North America, and their differences during precipitating and nonprecipitating conditions were also assessed for a five-year period. The differences between these two temperatures were generally larger for the non-precipitating cases than for the precipitating cases (Figure 2). The differences between $T_{a}$ and $T_{s}$ also exhibited notable temporal variability ranging from diurnal to seasonal (e.g., Figure 3). Additionally, the magnitude of their differences showed spatial variability that is associated with distinct land surface characteristics. This finding is corroborated by recent studies (e.g., Gallo et al. 2011; Bechtel, 2015).

Since the AIRS and MODIS sensors provide concurrent measurements of both $T_{a}$ and $T_{s}$, unique opportunities to assess their differences at the global scale exist. In this study, large-scale features of $T_{a}$ and $T_{s}$ were depicted well by the satellite estimates for the 13-year period. In general, larger $T_{s}$ than $T_{a}$ was evident over the globe during the day-time than during the nighttime. However, they showed noticeable differences over the desert regions (Figure 4). As expected, their differences also showed a seasonal cycle associated with solar heating (Figure 5). Desert regions have very few in-situ observations of $T_{a}$ and $T_{s}$ due to their uninhabitable environments. However, the Aqua clear-sky estimates are available over the global deserts; this bodes well for studies of the variability of $T_{a}$ and $T_{s}$ in the climate change perspective (Bechtel, 2015; Zhou and Wang, 2016). 
Additionally, $T_{s}$ estimates from MODIS and AIRS sensors were also inter-compared (Figure 6). Although both sensors are onboard the Aqua satellite, their spatial resolutions and measurement principles are different. The MODIS sensor provides $T_{s}$ estimates at finer spatial resolution than that from the AIRS sensor, which might lead to larger $T_{s}$ over the tropical regions from the MODIS estimates. Finally, $T_{s}$ and $T_{a}$ estimates from both sensors were evaluated against USCRN observations for 2009-2013. $T_{s}$ estimates derived from MODIS showed considerably larger biases and errors than those from AIRS estimates. The error characteristics also showed distinct differences during day and night times, and they also varied spatially (Figures 9 and 10). Larger discrepancies between MODIS-derived $T_{s}$ and ground-based observations were also recently reported over South China (Liu et al., 2017). Overall, the results reveal the need of extensive efforts to further improve $T_{s}$ retrieval algorithms.

Augmentation of ground-based observations of $T_{s}$ and $T_{a}$ over different parts of the globe is essential to better understand the error characteristics of the satellite-derived estimates. The infrared-based $T_{a}$ and $T_{s}$ estimates are limited to clear-sky conditions, and about $60 \%$ of the globe is usually covered by the cloud (Prigent et al., 2016). Passive microwave remote sensing has immense potential to retrieve these parameters under cloudy-sky conditions as well. Prigent et al. (2016) demonstrated an approach to estimate $T_{s}$ under all-weather conditions through passive land surface emissivity, and the estimated $T_{s}$ showed promising error characteristics. An empirical regression method by the combined use of effective $T_{a}$ from the MODIS and passive microwave brightness temperature measurements was also proposed to estimate surface level $T_{a}$ at finer spatial resolution under all-weather conditions (Jang et al., 2014). Additionally, the synergistic use of infrared and passive microwave estimates would essentially provide more accurate global $T_{a}$ and $T_{s}$ products at finer spatio-temporal resolutions. The study of $T_{a}$ and $T_{s}$ 
differences is crucial for many applications and highlights the importance of each parameter and its associated limitations. Additionally, $T_{a}$ and $T_{s}$ are inter-changeably used for different applications such as freeze and thaw detections. This study reveals that the difference in each temperature type may be significant enough to directly affect results in particular applications.

\section{Conclusions}

In this study, differences between $T_{a}$ and $T_{s}$ were assessed for a five-year period using the USCRN observations that covered a wide range of vegetation type, elevation and geography over the North America. The analysis was carried out for two specific times of the day corresponding to the overpass times of the Aqua satellite. The magnitudes of $T_{s}$ were generally found to be greater than $T_{a}$ during non-precipitating conditions. However, the differences between $T_{a}$ and $T_{s}$ were generally $2-3$ times smaller for precipitating conditions than non-precipitating conditions. Additionally, these differences showed considerable diurnal and seasonal variations. The differences between $T_{a}$ and $T_{s}$ were also assessed at the global scale using the AIRS estimates under clear-sky conditions for the period 2003 to 2015. The tropical regions showed about 5-20 ${ }^{\circ} \mathrm{C}$ higher $T_{s}$ estimates than $T_{a}$ estimates during the day-time, whereas opposite characteristics $\left(\sim 2-5{ }^{\circ} \mathrm{C}\right.$ cooler $T_{s}$ than $\left.T_{a}\right)$ were found over most parts of the globe during the night-time. The well-known seasonal cycle of $T_{a}$ and $T_{s}$ was well represented by the AIRS estimates in both hemispheres. Furthermore, $T_{s}$ estimates from AIRS and MODIS sensors were inter-compared for a 13-year period. Although large-scale features of $T_{s}$ were similar in both estimates, considerable differences in magnitudes were observed. Finally, $T_{a}$ and $T_{s}$ estimates from the AIRS and MODIS were evaluated against ground-based observations for the period of 2009 to 2013 . The error characteristics essentially varied with USCRN stations and no clear evidence of their 
dependency on land cover types or elevation was found. However, the MODIS-derived $T_{s}$ estimates generally showed larger biases and higher errors when compared to AIRS-derived estimates. The biases and errors gradually amplified with decrease (from finer to coarser) in spatial resolution. These results revealed that representativeness error should be taken into account when validating satellite-based temperature estimates with point observations. Moreover, there is a need for high-resolution satellite-based $T_{a}$ and $T_{s}$ estimates at the global scale for all-weather conditions.

Acknowledgements: The authors would like to thank the editor and anonymous reviewers for their constructive comments. The statements contained within the manuscript are not the opinions of the funding agency or the U.S. government; they reflect the authors' opinions only. MODIS/Aqua land surface temperature data obtained from the NASA EOSDID LP DAAC (https://lpdaac.usgs.gov/), Aqua/AIRS data products obtained from the GES DISC (https://disc.gsfc.nasa.gov/), USCRN observations obtained from the NOAA National Centers for Environmental Information (https://www.ncdc.noaa.gov/crn/), and MODIS-based $0.5 \mathrm{~km}$ global land cover climatology obtained from the USGS Land Cover Institute (https://landcover.usgs.gov/) are thankfully acknowledged.

Funding Information: This study was supported by the National Science Foundation (NSF) Research Experiences for Undergraduates (REU) under Grant 1560050, and by the Center for Remote Sensing and Earth System Sciences at the New York City College of Technology. This study was also partially supported by the Department of Defense Army Research Office under Grant W911NF-15-1-0070 and by the NASA under Grant NNH15ZDA001N. 


\section{References}

Ayanlade, A., 2016: Seasonality in the daytime and night-time intensity of land surface temperature in a tropical city area, Sci. Total Environ., 557-558, 415-424, doi:10.1016/j.scitotenv.2016.03.027.

Bell, J. E., M. A. Palecki, C. B. Baker, W. G. Collins, J. H. Lawrimore, R. D. Leeper, M. E. Hall, J. Kochendorfer, T. P. Meyers, T. Wilson, and H. J. Diamond, 2013: U.S. Climate Reference Network soil moisture and temperature observations, J. Hydrometeorol., 14, 977-988, doi:10.1175/JHM-D-12-0146.1.

Bechtel, B., 2015: A new global climatology of annual land surface temperature, Remote Sens., 7(3), 2850-2870, doi:10.3390/rs70302850.

Blackwell, W. J., 2012: Neural network Jacobian analysis for high-resolution profiling of the atmosphere, EURASIP J. Adv. Signal Process., 71, 1-11, doi:10.1186/1687-6180-2012-71.

Boylan, P., J. Wang, S. A. Cohn, E. Fetzer, E. S. Maddy, and S. Wong, 2015: Validation of AIRS version 6 temperature profiles and surface-based inversions over Antarctica using Concordiasi dropsonde data, J. Geophys. Res. - Atmos., 120, 992-1007, doi:10.1002/2014JD022551.

Broxton, P. D., X. Zeng, D. Sulla-Menashe, and P. A. Troch, 2014: A global land cover climatology using MODIS data, J. Appl. Meteorol. Climatol., 53, 1593-1605, doi:10.1175/JAMC-D-13-0270.1.

Cheval, S., and A. Dumitrescu, 2017: Rapid daily and sub-daily temperature variations in an urban environment, Clim. Res., 73, 233-246, doi:10.3354/cr01481.

Diamond, H. J., T. R. Karl, M. A. Palecki, C. B. Baker, J. E. Bell, R. D. Leeper, D. R. Easterling, J. H. Lawrimore, T. P. Meyers, M. R. Helfert, G. Goodge, and P. W. Thorne, 2013: U.S. Climate Reference Network after one decade of operations: status and assessment, Bull. Amer. Meteorol. Soc., 94, 489-498, doi:10.1175/BAMS-D-12-00170.1.

Didari, S., H. Norouzi, S. Zand-Parsa, R. Khanbilvardi, 2017: Estimation of daily minimum land surface air temperature using MODIS data in southern Iran, Theor. Appl. Climatol., 130, 1149-1161, doi:10.1007/s00704-016-1945-0.

Fabrizi, R., S. Bonafoni, and R. Biondi, 2010: Satellite and ground-based sensors for the urban heat island analysis in the city of Rome, Remote Sens., 2(5), 1400-1415, doi:10.3390/rs2051400. 
Gallo, K., R. Hale, D. Tarpley, and Y. Yu, 2011: Evaluation of the relationship between air and land surface temperature under clear- and cloudy-sky conditions, J. Appl. Meteorol. Climatol., 50, 767-775, doi:10.1175/2010JAMC2460.1.

Good, E. J., 2016: An in situ-based analysis of the relationship between land surface "skin" and screen-level air temperatures, J. Geophys. Res. - Atmos., 121, 8801-8819, doi:10.1002/2016JD025318.

Houser, P. R., G. J. De Lannoy, and J. P. Walker, 2010: Land surface data assimilation, In W. Lahoz, B. Khattatov, R. Menard (eds) Data Assimilation, Springer, Berlin, Heidelberg, 549-597, doi:10.1007/978-3-540-74703-1_21.

Jang, K., S. Kang, J. S. Kimball, and S. Y. Hong, 2014: Retrievals of all-weather daily air temperature using MODIS and AMSR-E data, Remote Sens., 6(9), 8387-8404, doi:10.3390/rs6098387.

Kang, H.-J., J.-M. Yoo, M.-J. Jeong, and Y.-I. Won, 2015: Uncertainties of satellite-derived surface skin temperatures in the polar oceans: MODIS, AIRS/AMSU, and AIRS only, Atmos. Meas. Tech., 8, 4025-4041, doi:10.5194/amt-8-4025-2015.

Lee, Y.-R., J.-M. Yoo, M.-J. Jeong, Y.-I. Won, T. Hearty, and D.-B. Shin, 2013: Comparison between MODIS and AIRS/AMSU satellite-derived surface skin temperatures, Atmos. Meas. Tech., 6, 445-455, doi:10.5194/amt-6-455-2013.

Liu, W., S. Chen, H. Jiang, C. Wang, and D. Li, 2017: Spatiotemporal analysis of MODIS land surface temperature with in situ meteorological observations and ERA-Interim reanalysis: The option of model calibration, IEEE J. Selected Topics Appl. Earth Obs. Remote Sens., 10, 1357-1371, doi:10.1109/JSTARS.2016.2645859.

Mazdiyasni, O., and A. AghaKouchak, 2015: Substantial increase in concurrent droughts and heatwaves in the United States, Proc. Nat. Acad. Sci., 112, 11484-11489, doi:10.1073/pnas.1422945112.

Moncet, J.-L., P. Liang, A. E. Lipton, J. F. Galantowicz, and C. Prigent, 2011: Discrepancies between MODIS and ISCCP land surface temperature products analyzed with microwave measurements, J. Geophys. Res., 116, D21105, doi:10.1029/2010JD015432.

Noi, P. T., M. Kappas, and J. Degener, 2016: Estimating daily maximum and minimum land air surface temperature using MODIS land surface temperature data and ground truth data in Northern Vietnam, Remote Sens., 8(12), 1002, doi:10.3390/rs8121002. 
Norouzi, H., M. Temimi, W. Rossow, C. Pearl, M. Azarderakhsh, and R. Khanbilvardi, 2011: The sensitivity of land surface emissivity estimates from AMSR-E at $\mathrm{C}$ and $\mathrm{X}$ bands to surface properties, Hydrol. Earth Syst. Sci., 15, 3577-3589, doi:10.5194/hess-15-35772011.

Norouzi, H., M. Temimi, A. AghaKouchak, M. Azarderakhsh, R. Khanbilvardi, G. Shields, and K. Tesfagiorgis, 2015: Inferring land surface parameters from the diurnal variability of microwave and infrared temperatures, Phys. Chem. Earth, 83-84, 28-35, doi:10.1016/j.pce.2015.01.007.

Oyler, J. W., S. Z. Dobrowski, Z. A. Holden, and S. W. Running, 2016: Remotely sensed land skin temperature as a spatial predictor of air temperature across the Conterminous United States, J. Appl. Meteorol. Climatol., 55, 1441-1457, doi:10.1175/JAMC-D-15-0276.1.

Parkinson, C. L., 2013: Summarizing the first ten years of NASA's Aqua mission, IEEE J. Selected Topics Appl. Earth Obs. Remote Sens., 6, 1179-1188, doi:10.1109/JSTARS.2013.2239608.

Prakash, S., H. Norouzi, M. Azarderakhsh, R. Blake, and K. Tesfagiorgis, 2016: Global land surface emissivity estimation from AMSR2 observations, IEEE Geosci. Remote Sens. Lett., 13, 1270-1274, doi:10.1109/LGRS.2016.2581140.

Prakash, S., H. Norouzi, M. Azarderakhsh, R. Blake, and R. Khanbilvardi, 2017: Potential of satellite-based land emissivity estimates for the detection of high-latitude freeze and thaw states, Geophys. Res. Lett., 44, 2336-2342, doi:10.1002/2017GL072560.

Prakash, S., H. Norouzi, M. Azarderakhsh, R. Blake, C. Prigent, and R. Khanbilvardi, 2018: Estimation of consistent global microwave land surface emissivity from AMSR-E and AMSR2 observations, J. Appl. Meteorol. Climatol., 57, 907-919, doi:10.1175/JAMC-D17-0213.1.

Prigent, C., C. Jimenez, and F. Aires, 2016: Towards all weather, long record, and real-time land surface temperature retrievals from microwave satellite observations, J. Geophys. Res. Atmos., 121, 5699-5717, doi:10.1002/2015JD024402.

Rahmstorf, S., G. Foster, and N. Cahill, 2017: Global temperature evolution: Recent trends and some pitfalls, Environ. Res. Lett., 12, 054001, doi:10.1088/1748-9326/aa6825. 
Ramamurthy, P., and M. Sangobanwo, 2016: Inter-annual variability in urban heat island intensity over 10 major cities in the United States, Sustainable Cities and Society, 26, 6575, doi:10.1016/j.scs.2016.05.012.

Ruzmaikin, A., H. H. Aumann, J. Lee, and J. Susskind, 2017: Diurnal cycle variability of surface temperature inferred from AIRS data, J. Geophys. Res. - Atmos., 122, 10928-20938, doi:10.1002/2016JD026265.

Shati, F., S. Prakash, H. Norouzi, and R. Blake, 2018: Assessment of differences between nearsurface air and soil temperatures for reliable detection of high-latitude freeze and thaw states, Cold Reg. Sci. Technol., 145, 86-92, doi:10.1016/j.coldregions.2017.10.007.

Sheng, Y., X. Liu, X. Yang, Q. Xin, C. Deng, and X. Li, 2017: Quantifying the spatial and temporal relationship between air and land surface temperatures of different land-cover types in Southeastern China, Int. J. Remote Sens., 38, 1114-1136, doi:10.1080/01431161.2017.1280629.

Stephens, G. L., and T. L'Ecuyer, 2015: The Earth's energy balance, Atmos. Res., 166, 195-203, doi:10.1016/j.atmosres.2015.06.024.

Susskind, J., J. M. Blaisdell, and L. Iredell, 2014: Improved methodology for surface and atmospheric soundings, error estimates, and quality control procedures: the atmospheric infrared sounder science team version-6 retrieval algorithm, J. Appl. Remote Sens., 8, 084994, doi:10.1117/1.JRS.8.084994.

Urban, M., J. Eberle, C. Huttich, C. Schmullius, and M. Herold, 2013: Comparison of satellitederived land surface temperature and air temperature from meteorological stations on the Pan-Arctic scale, Remote Sens., 5, 2348-2367, doi:10.3390/rs5052348.

Wan, Z., 2014: New refinements and validation of the collection-6 MODIS land-surface temperature/emissivity product, Remote Sens. Environ., 140, 36-45, doi:10.1016/j.rse.2013.08.027.

Yang, Y. Z., W. H. Cai, and J. Yang, 2017: Evaluation of MODIS land surface temperature data to estimate near-surface air temperature in Northeast China, Remote Sens., 9(5), 410, doi:10.3390/rs9050410.

Zhou, C., and K. Wang, 2016: Land surface temperature over global deserts: Mean, variability, and trends, J. Geophys. Res. - Atmos., 121, 14344-14357, doi:10.1002/2016JD025410. 
Table 1: Location, elevation, and land cover type of the U. S. Climate Reference Network (USCRN) stations used in this study

\begin{tabular}{|c|c|c|c|c|c|}
\hline $\begin{array}{l}\text { S. } \\
\text { No. }\end{array}$ & Station Name & Latitude & Longitude & Elevation (m) & LC Type \\
\hline 1. & Millbrook, NY & 41.79 & -73.74 & 142 & $\begin{array}{c}\text { Deciduous Broadleaf } \\
\text { Forests }\end{array}$ \\
\hline 2. & $\begin{array}{c}\text { Charlottesville, } \\
\text { VA }\end{array}$ & 38 & -78.47 & 206 & \multirow[t]{2}{*}{ Mixed Forests } \\
\hline 3. & Darrington, WA & 48.54 & -121.45 & 110 & \\
\hline 4. & Williams, AZ & 35.76 & -112.34 & 1821 & \multirow[t]{2}{*}{ Open Shrublands } \\
\hline 5. & Monahans, TX & 31.62 & -102.81 & 828 & \\
\hline 6. & Selma, AL & 32.46 & -87.24 & 63 & \multirow{3}{*}{ Grasslands } \\
\hline 7. & Manhattan, KS & 39.1 & -96.61 & 357 & \\
\hline 8. & Wolf Point, MT & 48.31 & -105.1 & 632 & \\
\hline 9. & Merced, CA & 37.24 & -120.88 & 24 & \multirow{6}{*}{ Croplands } \\
\hline 10. & Sebring, FL & 27.15 & -81.37 & 46 & \\
\hline 11. & Des Moines, IA & 41.56 & -93.29 & 261 & \\
\hline 12. & Chillicothe, $\mathrm{MO}$ & 39.87 & -93.15 & 255 & \\
\hline 13. & Blackville, SC & 33.36 & -81.33 & 99 & \\
\hline 14. & Aberdeen, SD & 45.71 & -99.13 & 597 & \\
\hline 15. & Watkinsville, GA & 33.78 & -83.39 & 218 & \multirow{5}{*}{$\begin{array}{l}\text { Cropland/Natural } \\
\text { Vegetation Mosaic }\end{array}$} \\
\hline 16. & Lafayette, LA & 30.09 & -91.87 & 11 & \\
\hline 17. & Limestone, ME & 46.96 & -67.88 & 239 & \\
\hline 18. & Coshocton, $\mathrm{OH}$ & 40.37 & -81.78 & 295 & \\
\hline 19. & Crossville, TN & 36.01 & -85.13 & 578 & \\
\hline
\end{tabular}




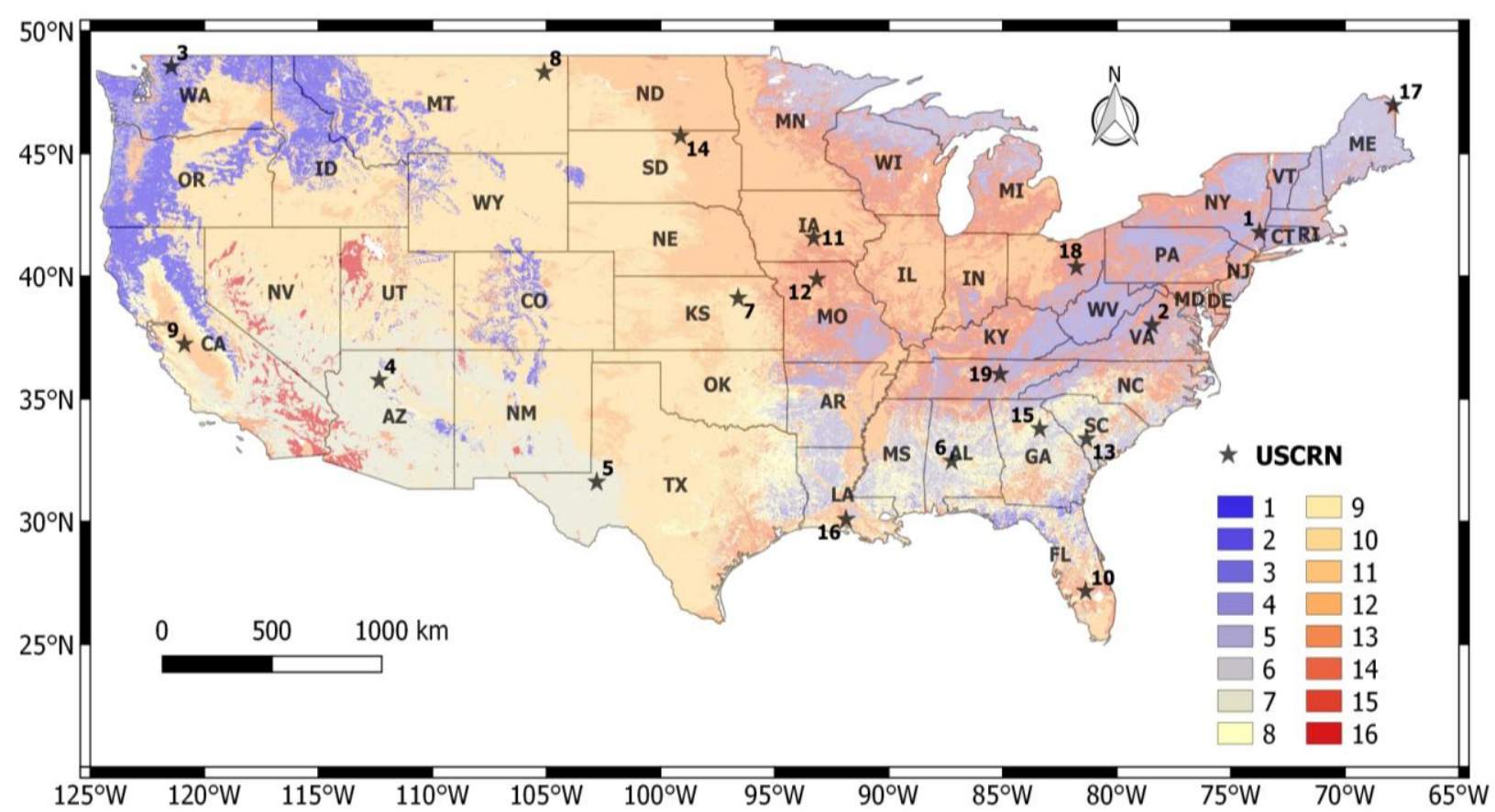

Figure 1: Spatial distributions of MODIS-based land cover type over the North America. Locations of the U. S. Climate Reference Network (USCRN) stations used in this study are also indicated and the station numbers are reference to Table 1. The color legend 1 to 16 corresponds to Evergreen Needleleaf Forests, Evergreen Broadleaf Forests, Deciduous Needleleaf Forests, Deciduous Broadleaf Forests, Mixed Forests, Closed Shrublands, Open Shrublands, Woody Savannas, Savannas, Grasslands, Permanent Wetlands, Croplands, Urban and Built-Up, Cropland/Natural Vegetation Mosaic, Snow and Ice, and Barren or Sparsely Vegetated, respectively. 

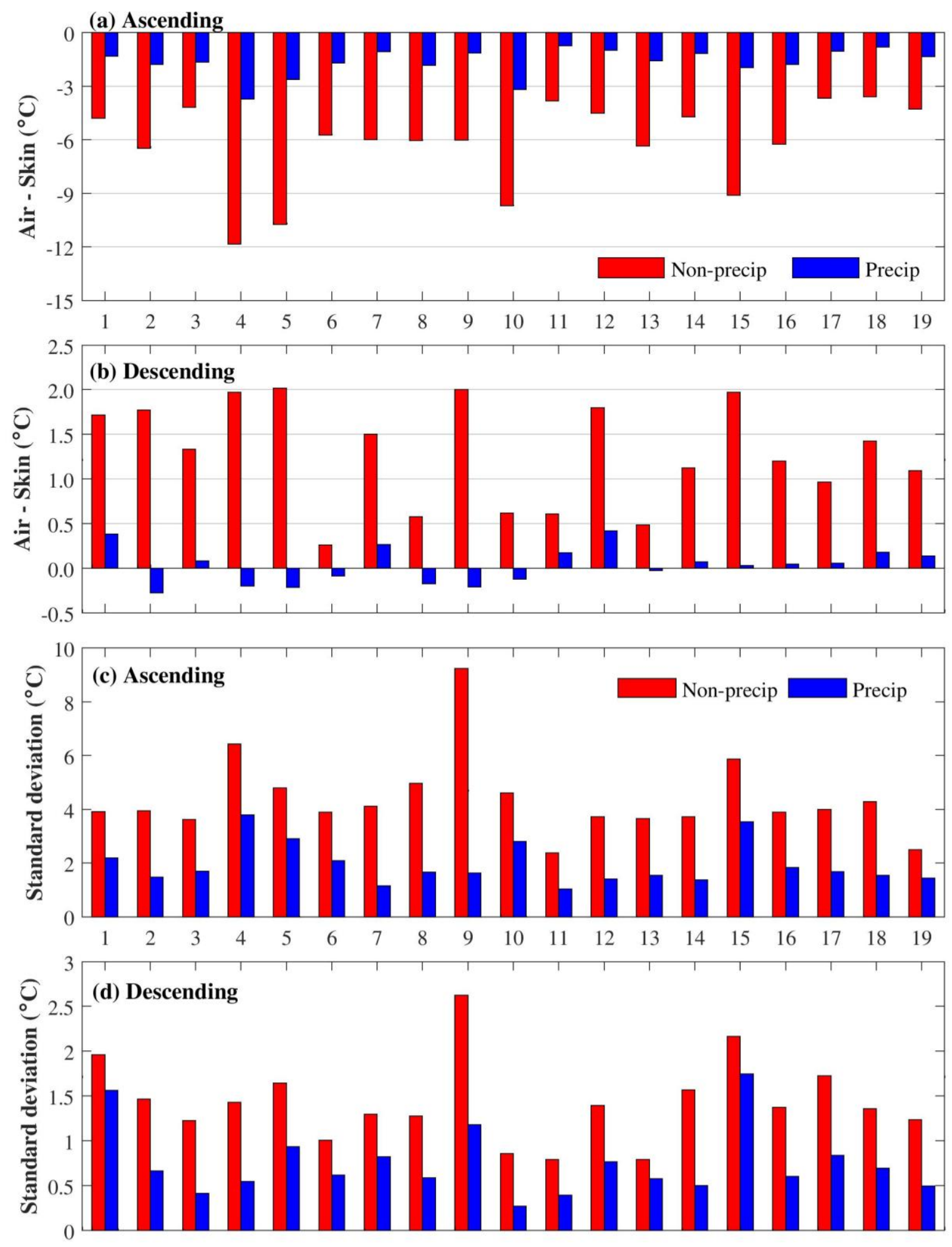

Figure 2: Differences between air and skin temperatures (a, b) and their standard deviations (c, d) for the selected 19 ground-based stations of Table 1 during precipitating and non-precipitating cases (2009-2013). The observation timings of USCRN stations are chosen similar to timings of ascending ( $a, c)$ and descending $(b, d)$ overpasses of the Aqua satellite. 

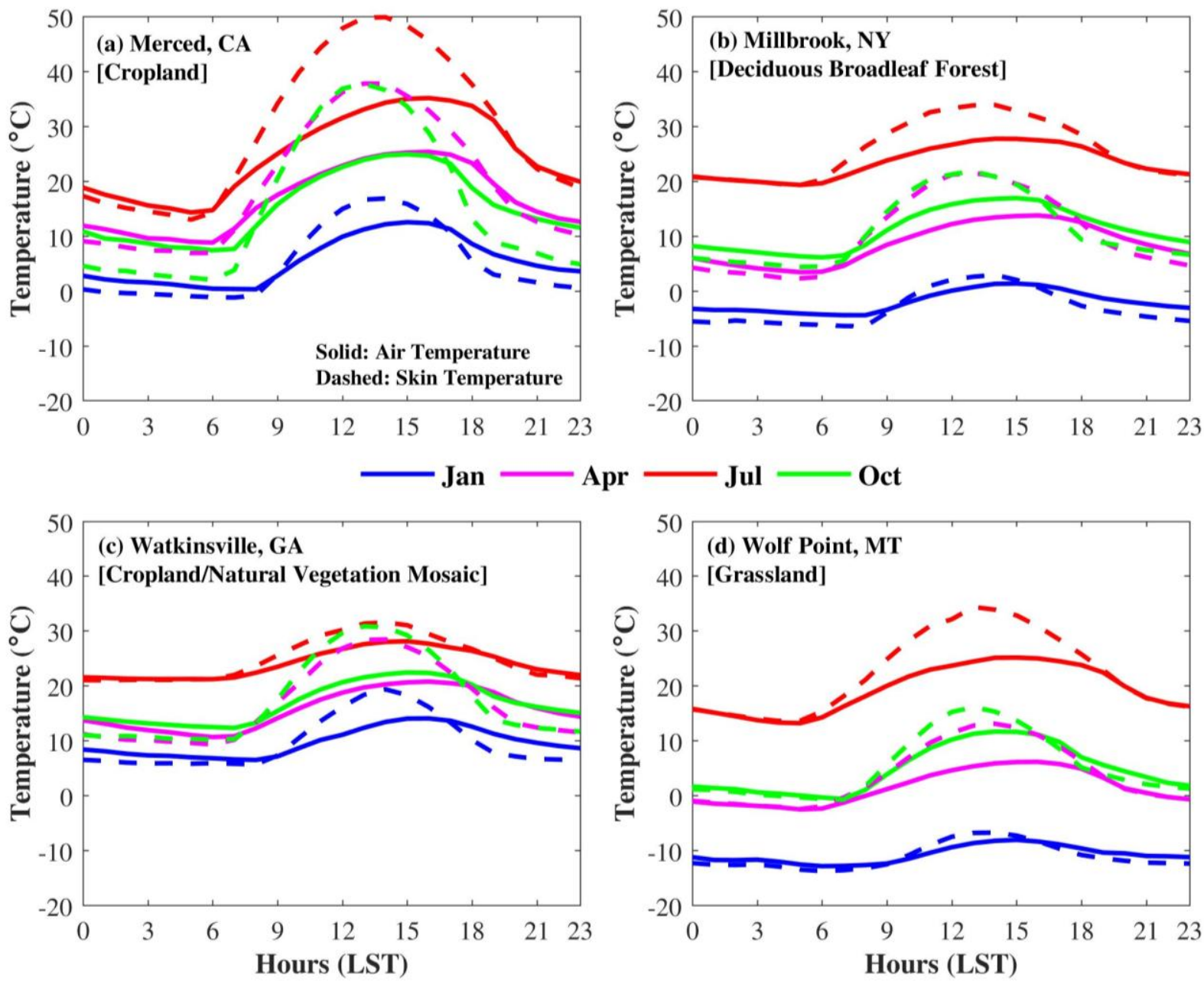

Figure 3: Diurnal variations of air and skin temperatures for the months of January, April, July, and October 2013 from hourly ground-based observations. Land cover types of each USCRN stations are also mentioned. 


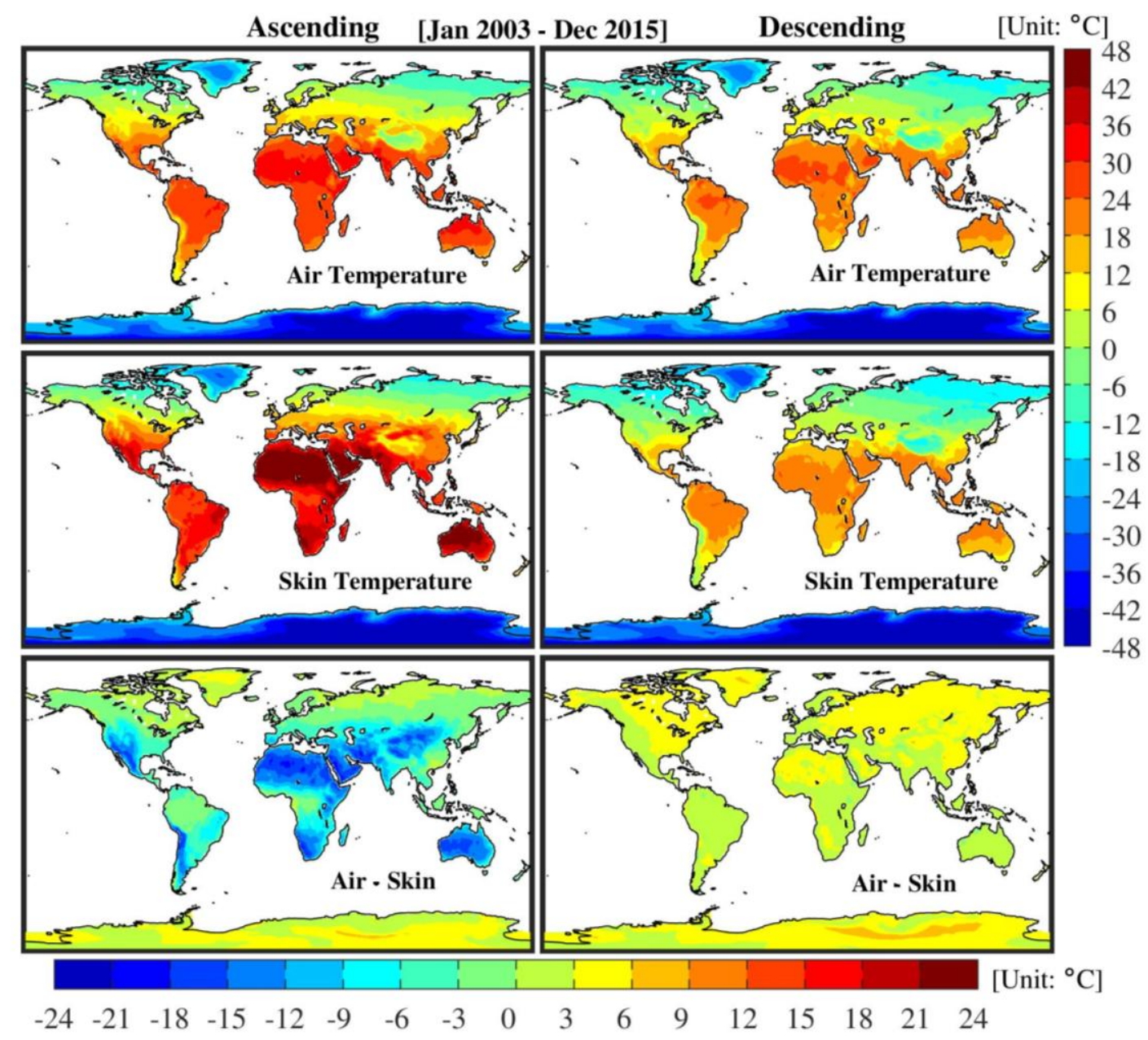

Figure 4: Spatial distributions of mean near-surface air and skin temperatures, and their differences for ascending and descending orbits of the AIRS sensor for the period 2003-2015. 


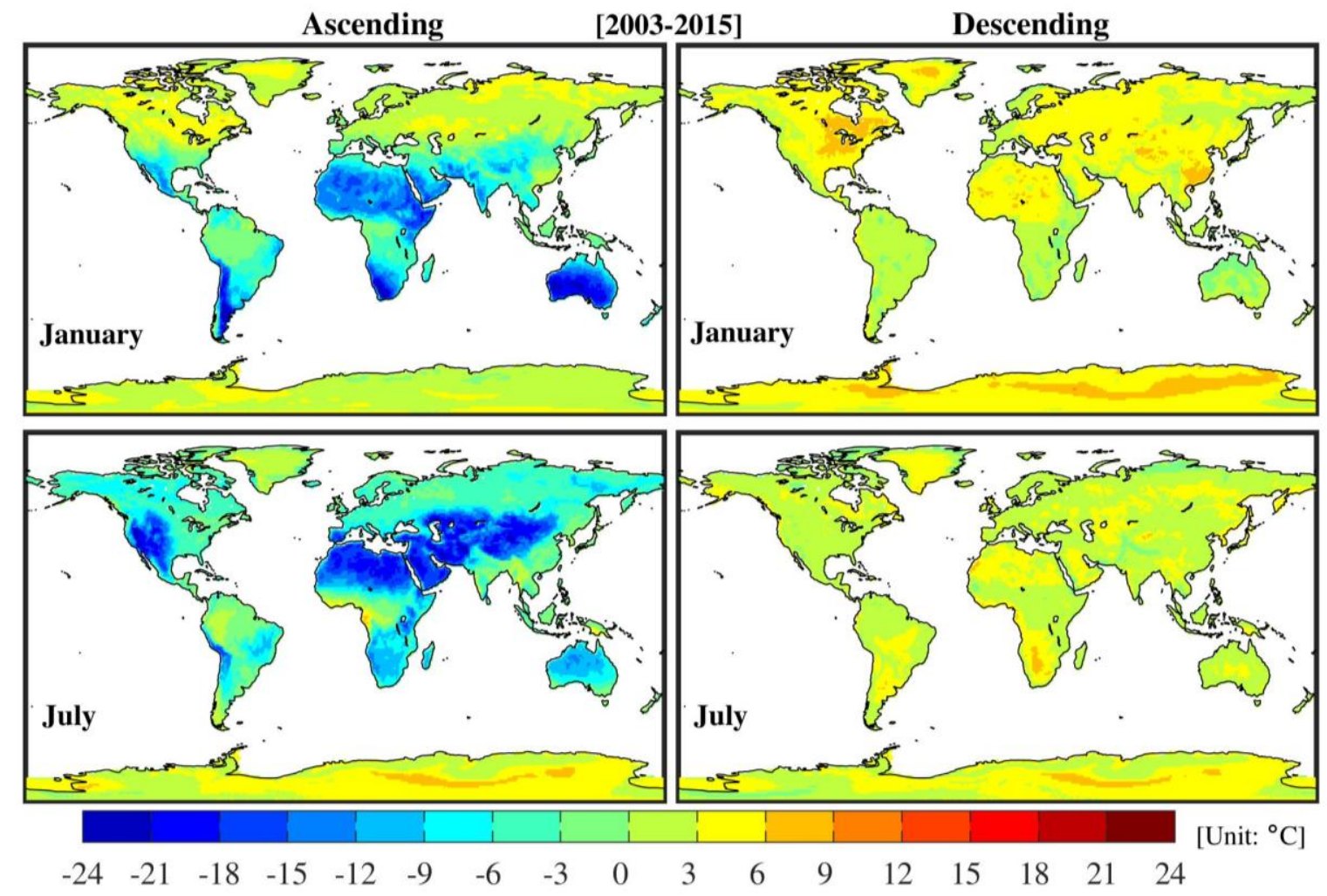

Figure 5: Spatial distributions of mean difference between near-surface air and skin temperatures (2003-2015) for ascending and descending orbits of the AIRS sensor averaged for the months of January and July. 
Skin Temperature for January 2012 [Ascending]

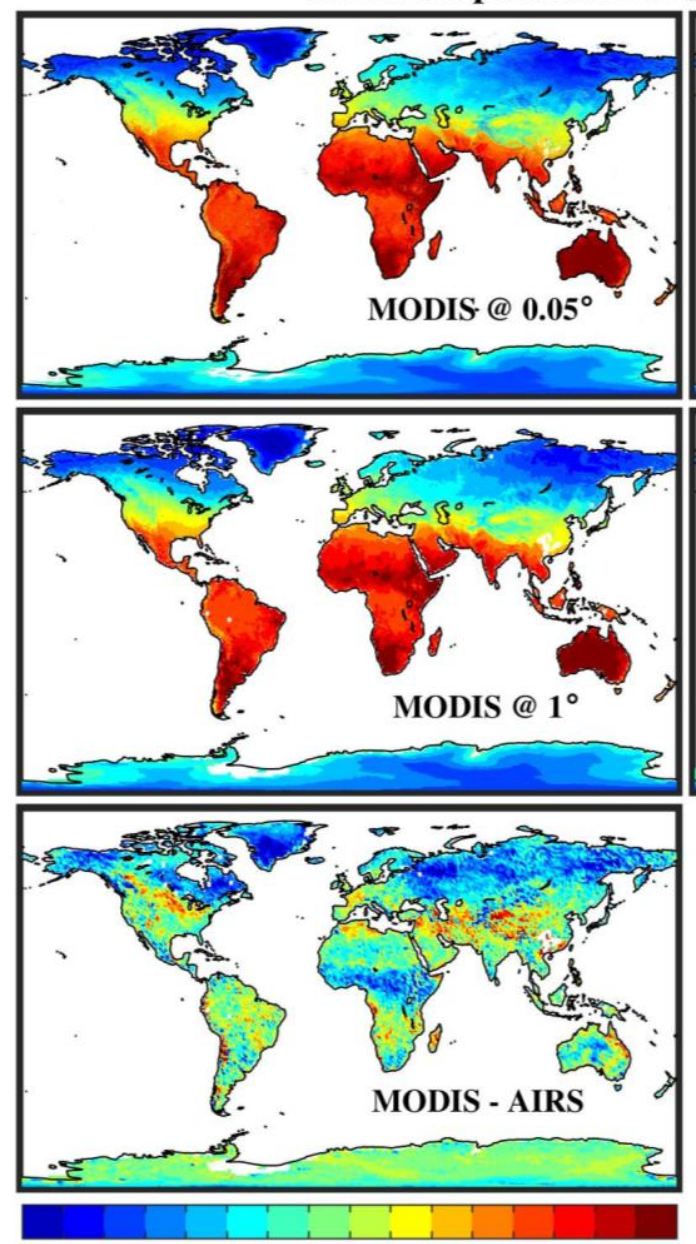

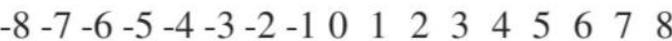
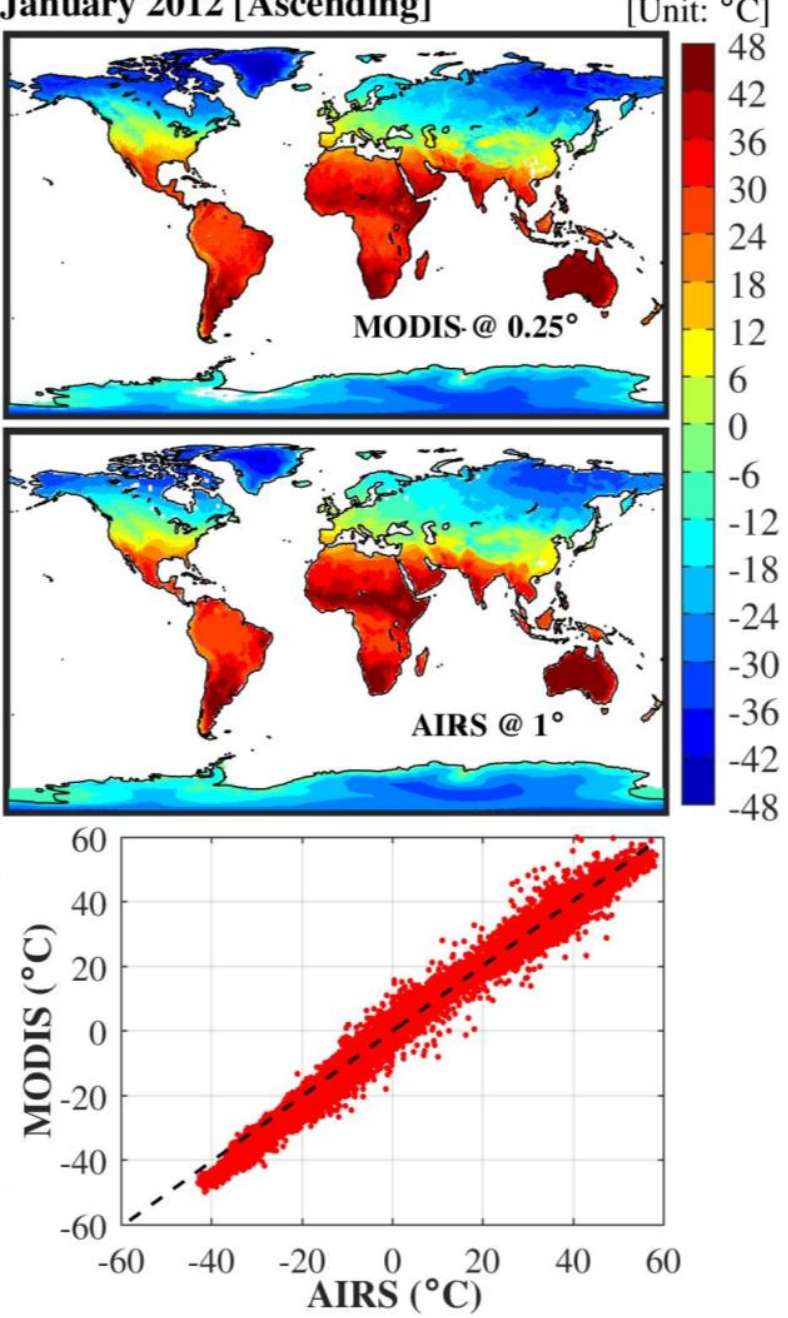

Figure 6: Mean monthly skin temperatures from the MODIS, and from the AIRS for the ascending orbits of January 2012. The spatial distributions of difference between MODIS and AIRS skin temperatures at $1^{\circ}$ latitude/longitude resolution, and corresponding scatter plot are shown in bottom-right panel. 

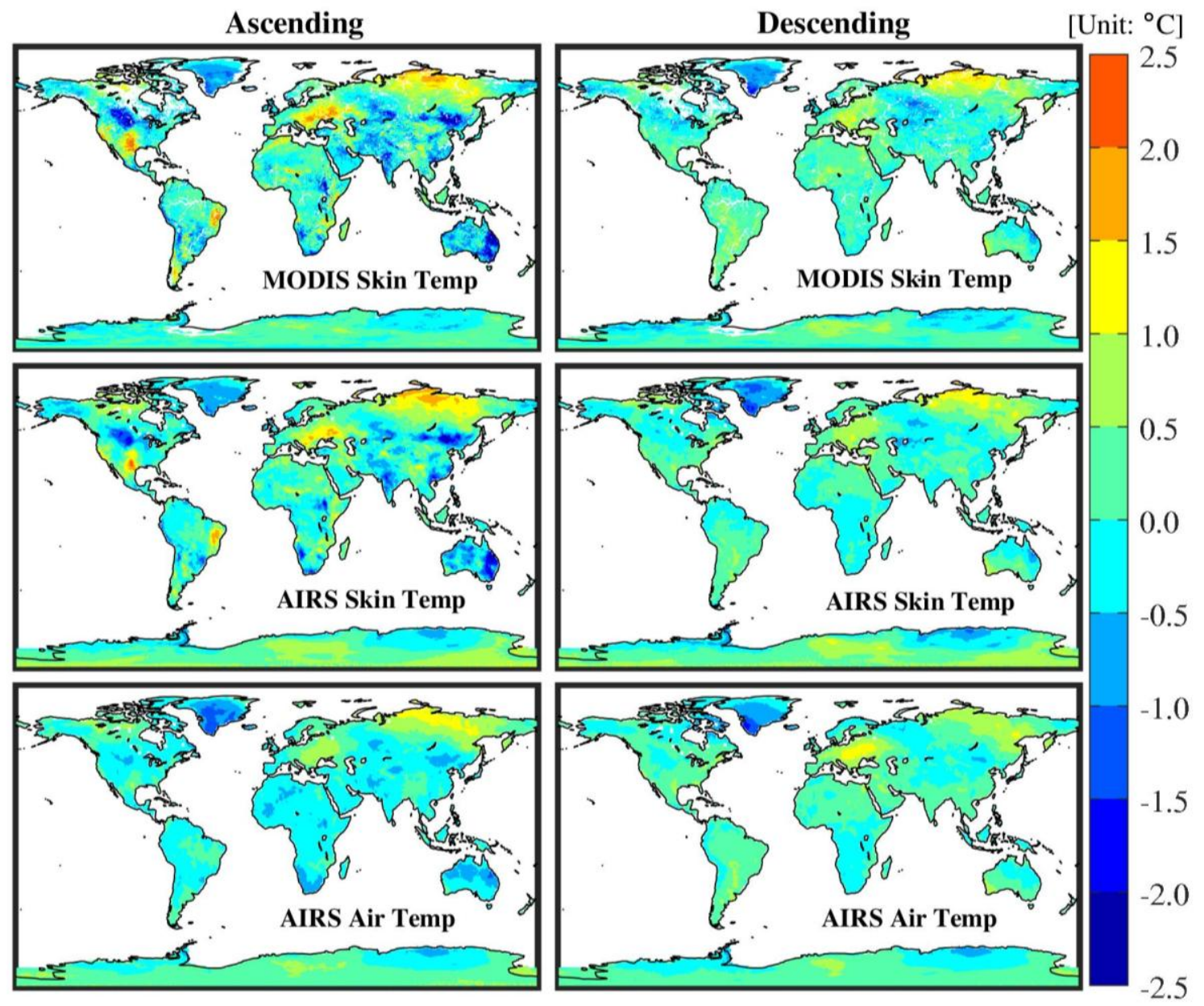

Figure 7: Spatial distributions of differences in 5-year mean skin and air temperatures for ascending and descending orbits of the MODIS and the AIRS sensors at the end (2011-2015) and at the beginning (2003-2007) of the study period. 


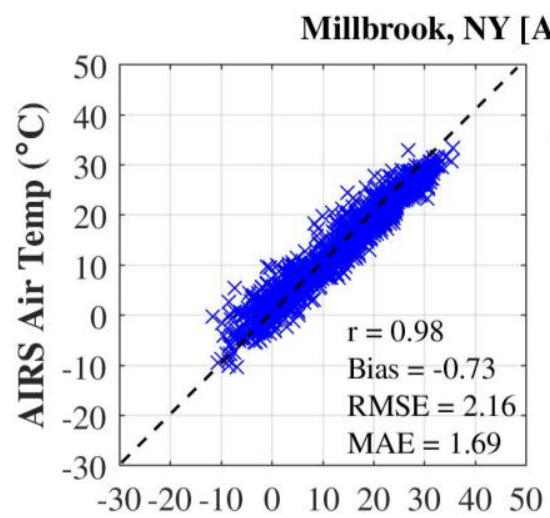

USCRN Air Temp $\left({ }^{\circ} \mathrm{C}\right)$

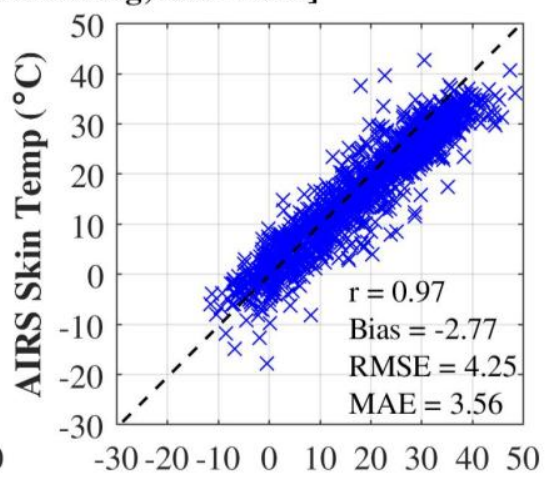

USCRN Skin Temp $\left({ }^{\circ} \mathrm{C}\right)$

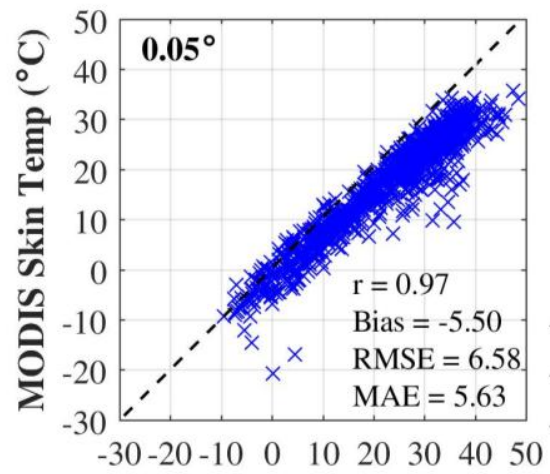

USCRN Skin Temp $\left({ }^{\circ} \mathrm{C}\right)$

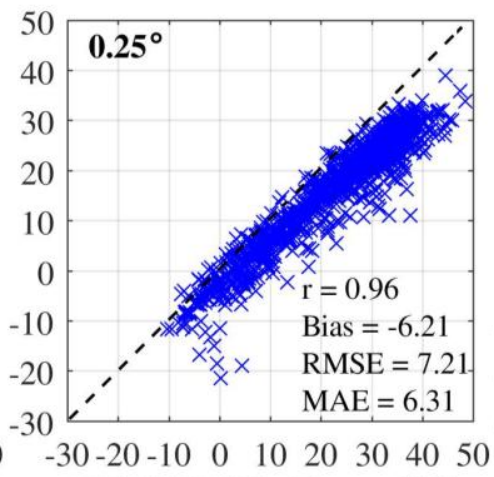

USCRN Skin Temp $\left({ }^{\circ} \mathrm{C}\right)$

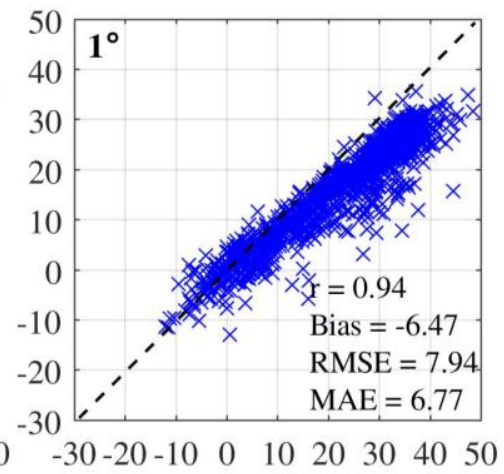

USCRN Skin Temp $\left({ }^{\circ} \mathrm{C}\right)$

Figure 8: Scatter plots showing comparison of day-time AIRS air and skin temperatures, and MODIS skin temperatures at three distinct spatial resolutions with ground-based observations at Millbrook, NY for the period 2009-2013. 

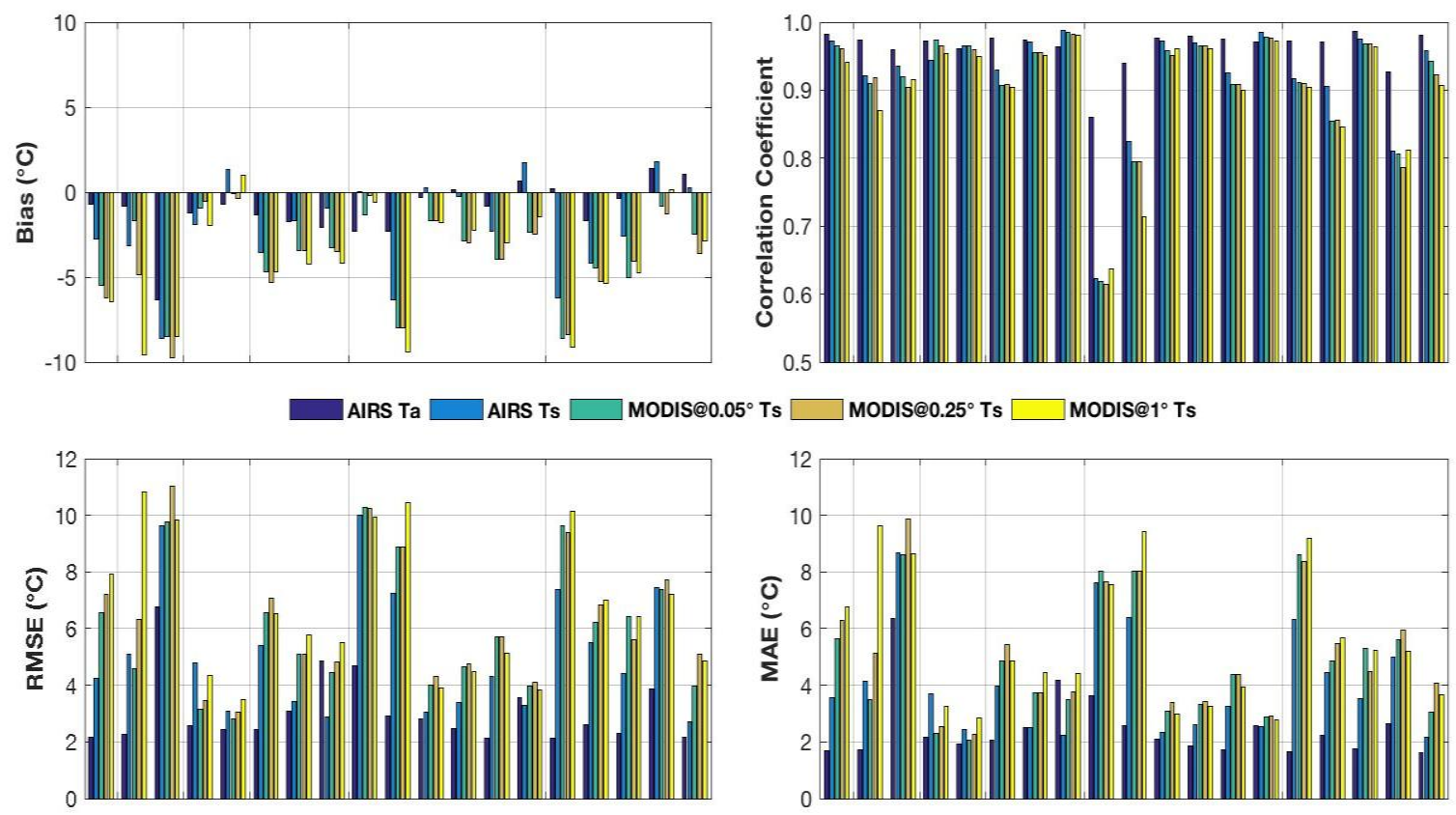

Figure 9: Bias, correlation coefficient, RMSE, and MAE after comparing day-time AIRS air and skin temperatures, and MODIS skin temperatures at three distinct spatial resolutions with 19 ground-based observations for the period 2009-2013. The order of the USCRN stations at x-axis is same as Table 1 . 

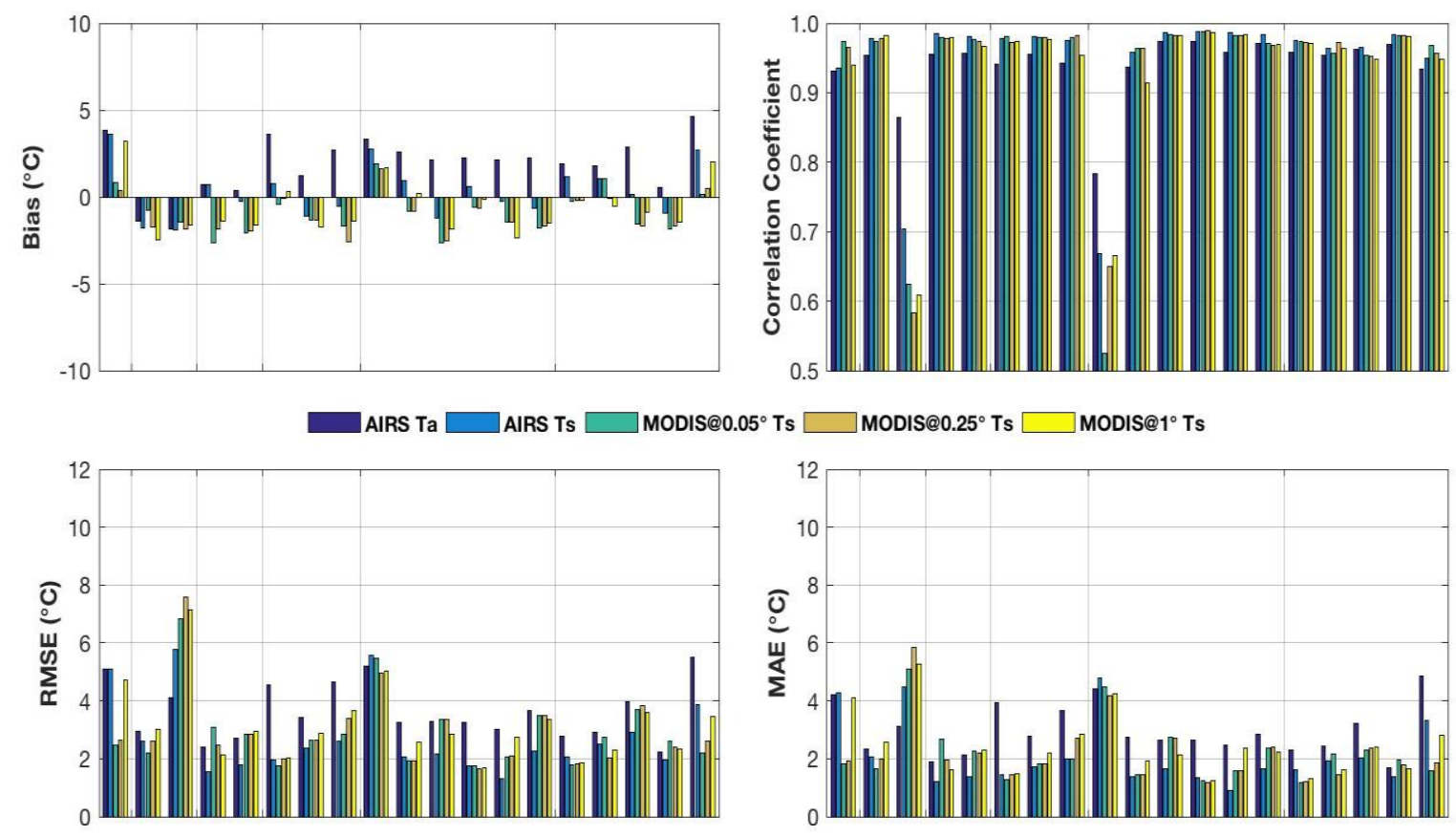

Figure 10: Bias, correlation coefficient, RMSE, and MAE after comparing night-time AIRS air and skin temperatures, and MODIS skin temperatures at three distinct spatial resolutions with 19 ground-based observations for the period 2009-2013. The order of the USCRN stations at $x$-axis is same as Table 1 . 